\title{
Later breeding in northern gannets in the eastern Atlantic
}

\author{
Sarah Wanless ${ }^{1,5, *}$, Michael P. Harris ${ }^{1,5}$, Sue Lewis ${ }^{2}$, Morten Frederiksen ${ }^{3}$, \\ Stuart Murray ${ }^{4}$ \\ ${ }^{1}$ Centre for Ecology and Hydrology, Hill of Brathens, Banchory AB31 4BW, UK \\ ${ }^{2}$ Institute of Evolutionary Biology, King's Buildings, University of Edinburgh, Edinburgh EH9 3JT, UK \\ ${ }^{3}$ National Environment Research Institute, University of Aarhus, Frederiksborgvej 399, 4000 Roskilde, Denmark \\ ${ }^{4}$ Murray Consultancy, Easter Craigie Dhu, Cardney, Dunkeld, Perthshire PH8 0EY, UK \\ ${ }^{5}$ Present address: Centre for Ecology and Hydrology, Bush Estate, Penicuik EH26 0QB, UK
}

\begin{abstract}
Species with breeding distributions spanning a broad latitudinal range typically experience a correspondingly wide range of environmental conditions, and may also be subject to temporal changes in conditions operating either across their range or more locally. Phenological records are potentially useful for elucidating how species adjust to this spatial and temporal variation, particularly in the context of responses to climate change, and have been widely used in studies of terrestrial birds. In contrast, despite the fact that many marine environments are also changing markedly as a result of climate warming, studies of the phenology of seabirds are comparatively rare. We used data from a wide range of sources to examine trends in breeding time in relation to latitude $\left(49\right.$ to $\left.62^{\circ} \mathrm{N}\right)$ and year (1980 to 2007) in the northern gannet Morus bassanus at 17 colonies in the eastern Atlantic. We found significant spatial and temporal effects but no significant interaction between latitude and year, indicating a consistent shift in breeding time at gannetries in the central and southern parts of the breeding range between 1980 and 2007. On average, median hatch date became $1.98 \mathrm{~d}$ later for every $1^{\circ}$ latitude shift north, such that breeding in the Faeroe Islands was 26 d later than in northern France, and breeding was delayed by $0.21 \mathrm{~d} \mathrm{yr}^{-1}$, i.e. 6 d later in 2007 compared to 1980. There was no evidence that the trend towards later breeding was related to temporal changes in either local (late-winter sea surface temperature) or large-scale (winter North Atlantic Oscillation) ocean climate. We believe that this is the first evidence of a trend towards later breeding in a marine predator across a major part of its breeding range. More generally, our findings accord with other recent studies suggesting contrasting phenological responses between marine and terrestrial north temperate birds.
\end{abstract}

KEY WORDS: Phenology · Morus bassanus $\cdot$ Seabirds $\cdot$ Climate change $\cdot$ Monitoring $\cdot$ Latitude Hydrobiological conditions

\section{INTRODUCTION}

Species with breeding distributions spanning a broad latitudinal range typically experience a correspondingly wide range of environmental conditions, for example in terms of day length, temperature and ecosystem type. Superimposed on this spatial variability there may also be temporal changes operating either across the range or more locally. One way in which species can adapt to this spatial and temporal variation is to adjust breeding phenology, and pheno- logical records have proved extremely useful for elucidating both latitudinal patterns and responses to changing environmental conditions, particularly climate change (Hopkins 1938, Walther et al. 2002, Parmesan \& Yohe 2003). Terrestrial birds have figured prominently in such analyses and, in general, have shown trends towards later breeding with increasing latitude and, in recent years, earlier breeding in association with increasing temperature (Crick et al. 1997, Crick \& Sparks 1999, Both et al. 2004, Crick 2004). Many seabird species have latitudinally wide breeding 
ranges, and there has been a global rise in sea temperatures in recent decades (Levitus et al. 2000). However, phenological studies of marine birds are rare, estimates of latitudinal effects generally lacking and the available findings on temporal changes equivocal with breeding apparently advancing in some cases and becoming later in others (Aebischer et al. 1990, Durant et al. 2004, Frederiksen et al. 2004, Barbraud \& Weimerskirch 2006, Møller et al. 2006, Reed et al. 2006). Part of the imbalance between the number of phenological papers published on terrestrial and marine birds may be due to phenology not being routinely recorded in seabird monitoring programmes. However, many other aspects of seabird breeding biology are well monitored and we were able to utilise data from these sources to reconstruct a phenological dataset extending back over nearly 3 decades.

The northern gannet Morus bassanus (hereafter gannet) breeds in a limited number of well-defined colonies, and in the eastern Atlantic the species has a breeding range extending from 49 to $70^{\circ} \mathrm{N}$ (Nelson 1978) that encompasses several well-defined marine

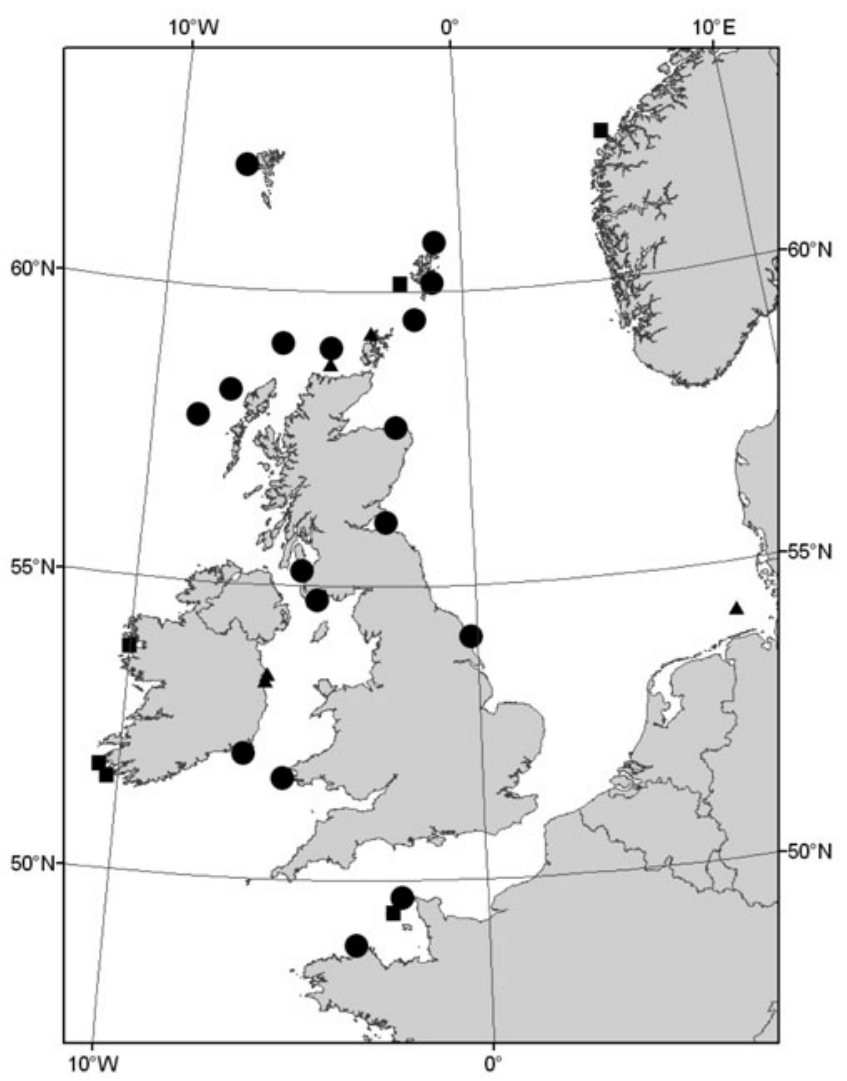

Fig. 1. Morus bassanus. Locations of northern gannet colonies in the eastern Atlantic south of $62^{\circ} \mathrm{N}$. ( ) : colonies used in the analysis; ( $\mathbf{\square})$ : colonies where no phenological data were available; (4): colonies founded between 1980 and 2007 and therefore not included in the present study regions with differing physical and ecological characteristics (Beaugrand et al. 2002a). It is therefore likely that environmental conditions vary among breeding colonies, and temporal changes may be out of phase between widely separated gannetries. Until recently it was thought that while the timing of breeding varied among gannet colonies, laying date at individual colonies showed rather little annual variation (Nelson 1978, 2002), except at newly formed gannetries where breeding initially became earlier, presumably as the proportion of older and/or more experienced birds in the breeding population increased (Nelson 1978, Wanless et al. 1996). However, visits to several gannetries in Scotland in recent years found that chicks were much younger than expected based on past experience (Zonfrillo 2005, Nelson 2006, 2007, Okill 2007 , Hunt \& Nelson 2008).

Our aim was to assess whether these reports signalled a change in gannet phenology in the eastern Atlantic and, if so, to quantify the rate and extent of the change. Although no phenology data were available for colonies at the northern edge of the breeding range, coverage of colonies at the centre and southern edge was good between 1980 and 2007. Our dataset included records from 17 colonies between $49^{\circ} \mathrm{N}$ (Rouzic, Sept Isles, France, the southernmost colony in the eastern Atlantic) and $62^{\circ} \mathrm{N}$ (Mykineshólmur, Faeroe Islands) (Fig. 1). Together these colonies made up 67 and $63 \%$ of the extant gannetries within the range shown in Fig. 1 in the mid-1980s and 2004, respectively, and 85 and $87 \%$ of the respective breeding populations (Murray \& Wanless 1986, Wanless et al. 2005b). Our specific aims were to test for (1) a latitudinal trend in gannet phenology; (2) a systematic change in timing of breeding, specifically for any evidence of a shift towards later breeding; and (3) an interaction in the relationships between breeding time and latitude and year that would indicate regional variation in phenological responses over this part of the gannet's breeding range. In addition, we tested whether spatial and temporal variation in timing of breeding was related to local and/or large-scale climate.

\section{METHODS}

Although annual estimates of timing of breeding are not routinely collected for gannets, colonies are visited for detailed monitoring of breeding success, aerial and land-based photographic surveys, and to ring or harvest chicks. By going back through these various sources it proved possible to derive time series of annual colony-specific estimates of timing of breeding for 17 colonies between 1980 and 2007 (Table 1, Fig. 1). 
Most estimates of the timing of breeding were obtained by back-calculating hatch dates of chicks after the majority of eggs had hatched. Gannet nests are conspicuous, and the breeding cycle is protracted (incubation 44 d, chick rearing ca. 90 d) (Nelson 2002). Chicks were aged into weekly categories using size and plumage characteristics of known-aged chicks (Nelson 1978, 2002), either in the field, often in conjunction with colony censuses (Murray \& Wanless 1986, Wanless et al. 2005b), or from photographs taken either opportunistically or during surveys of other species, e.g. grey seals Halichoerus grypus. Breeding tends to be later in newly colonised areas, particularly around the fringes of colonies (Nelson 1978, 2002); therefore, wherever possible, samples were obtained from several different parts of the colony. An annual median hatching date (hereafter termed annual hatch date) was calculated for each colony using the midpoint of each age category (e.g. for Week 3, 15 to $21 \mathrm{~d}$ $=18 \mathrm{~d}$ ) and including nests where birds were incubating or brooding chicks too small to be clearly visible. Incubators and small chicks always comprised $<50 \%$ of the sample $(90 \%$ cases $<10 \%)$. In a few colonies, regular checks were made during the laying, hatching or fledging periods and these were used to obtain an annual hatch date assuming incubation and fledging periods of 44 and 90 d, respectively (Nelson 2002). Qualitative observations totalling 60 colony-years were also available for 8 of the colonies (Great Saltee, Ailsa Craig, St. Kilda, Sula Sgeir, Sule Stack, Hermaness, Bass Rock, Noss) that were visited regularly by bird ringers, bird fowlers or reserve wardens.

Hatch dates were converted to Day of year for analysis. We tested whether timing of breeding showed latitudinal or temporal trends, and also whether there was a relationship with local or large-scale climate. Local climate was quantified as mean annual late-winter (February-March) mean sea surface temperature (SST), averaged over the $1^{\circ} \times 1^{\circ}$ cell containing the colony and its (up to) 8 neighbours. This was then decomposed for each colony into an overall mean SST, which could affect spatial patterns in timing of breeding, and annual anomalies, which could be related to year-to-year variation in phenology. Large-scale climate was represented by the principal componentbased winter North Atlantic Oscillation (NAO) index. SST data were downloaded from the International Comprehensive Ocean-Atmosphere Data Set (http:// icoads.noaa.gov), and NAO data from www.cgd.ucar. edu/cas/jhurrell/indices.html.

The model setup used was a restricted maximum likelihood linear mixed-effect model (Patterson \& Thompson 1971), with random colony and year effects. The statistical significance of fixed effects was evaluated using Wald $\chi^{2}$ tests. All statistical analyses were performed in SAS v. 9.1.

Table 1. Morus bassanus. Colonies from which annual estimates of the timing of hatching of northern gannets were available between 1980 and 2007

\begin{tabular}{|c|c|c|c|}
\hline Colony & Position & Years & Source (pers. comm. unless noted) \\
\hline Rouzic & $48.90^{\circ} \mathrm{N}, 3.43^{\circ} \mathrm{W}$ & $1990-2005,2007$ & F. Siorat \\
\hline Les Etacs & $49.70^{\circ} \mathrm{N}, 2.25^{\circ} \mathrm{W}$ & $1984,1994,2007$ & I. Buxton, M. Hill, S. Wanless \\
\hline Great Saltee & $52.12^{\circ} \mathrm{N}, 6.60^{\circ} \mathrm{W}$ & $1984,2000,2003$ & O. Merne, S. Lewis, S. Wanless \\
\hline Grassholm & $51.72^{\circ} \mathrm{N}, 5.48^{\circ} \mathrm{W}$ & $1984,2004,2006-07$ & M. Alexander, S. Votier, S, Wanless \\
\hline Bempton & $54.13^{\circ} \mathrm{N}, 0.17^{\circ} \mathrm{W}$ & $1984-85,2000,2007$ & $\begin{array}{l}\text { S. J. Holloway, I. T. Rowlands, C. Gray, } \\
\text { L. McKenzie }\end{array}$ \\
\hline Scar Rocks & $54.75^{\circ} \mathrm{N}, 4.67^{\circ} \mathrm{W}$ & $1984,1989,2007$ & $\begin{array}{l}\text { M. F. Carrier, J. Skilling, R. Smith, D. Thompson, } \\
\text { A. Hall }\end{array}$ \\
\hline Ailsa Craig & $55.25^{\circ} \mathrm{N}, 5.13^{\circ} \mathrm{W}$ & $1982,2000,2004,2007$ & T. Begg, B. Zonfrillo, S. Murray \\
\hline Bass Rock & $56.08^{\circ} \mathrm{N}, 2.63^{\circ} \mathrm{W}$ & $1984,2000-01,2004-07$ & $\begin{array}{l}\text { J. B. Nelson, S. Lewis, M. P. Harris, J. Hunt, } \\
\text { Nelson }(2006,2007)\end{array}$ \\
\hline Troup Head & $57.70^{\circ} \mathrm{N}, 2.30^{\circ} \mathrm{W}$ & $\begin{array}{l}1990-92,1994,1996-97 \\
2000-05,2007\end{array}$ & S. Wanless \\
\hline St. Kilda & $57.82^{\circ} \mathrm{N}, 8.57^{\circ} \mathrm{W}$ & $1980,1985,2007$ & S. Wanless, S. Murray, S. Money \\
\hline Flannan Isles & $58.28^{\circ} \mathrm{N}, 7.59^{\circ} \mathrm{W}$ & 1985,2007 & S. Murray, D. Thompson, A. Hall \\
\hline Sule Stack & $59.03^{\circ} \mathrm{N}, 4.40^{\circ} \mathrm{W}$ & $1986,2003,2005,2007$ & E. Meek, J. Blackburn, D. Thompson, A. Hall \\
\hline Sula Sgeir & $59.10^{\circ} \mathrm{N}, 5.98^{\circ} \mathrm{W}$ & 1986,2007 & S. Murray, D. Thompson, A. Hall \\
\hline Fair Isle & $59.53^{\circ} \mathrm{N}, 1.65^{\circ} \mathrm{W}$ & $1984,1994,2000,2007$ & $\begin{array}{l}\text { N. Riddiford, G. Thompson, D. de Palacio, } \\
\text { B. McCallum }\end{array}$ \\
\hline Noss & $60.15^{\circ} \mathrm{N}, 1.02^{\circ} \mathrm{W}$ & $1984,2005-07$ & $\begin{array}{l}\text { J. H. Dickson, G. A. Tyler, } \\
\text { Sykes \& Bliss }(2005,2006), \text { Ash \& Dodd (2007) }\end{array}$ \\
\hline Hermaness & $60.83^{\circ} \mathrm{N}, 0.92^{\circ} \mathrm{W}$ & $1984,1986,2000,2005-07$ & $\begin{array}{l}\text { I. S. Robertson, S. Wanless, C. C. Rodger, } \\
\text { Thomas (2005), Okill (2007) }\end{array}$ \\
\hline Mykineshólmur & $62.10^{\circ} \mathrm{N}, 7.58^{\circ} \mathrm{W}$ & 1985,2007 & B. Olsen \\
\hline
\end{tabular}




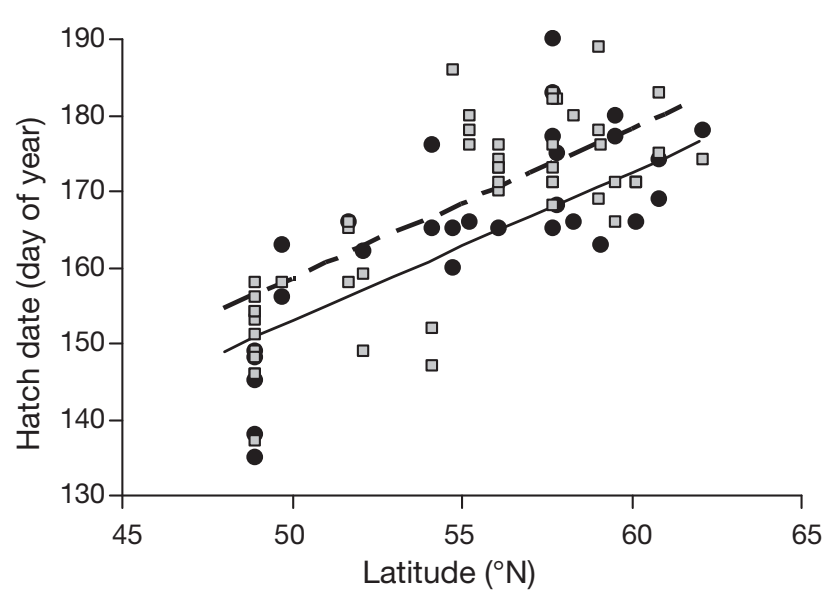

Fig. 2. Morus bassanus. Annual median hatch dates at gannet colonies in the eastern Atlantic south of $62^{\circ} \mathrm{N}$. ( $\bullet$ : 1980 to 1994; (): 1995 to 2007. The trend towards later breeding is illustrated by the fitted lines for relationships between hatch date and latitude in 1980 (solid line) and 2007 (dashed line)

\section{RESULTS}

We found significant and positive effects of latitude and year on gannet hatch dates (latitude: $\chi^{2}=42.81$, $\mathrm{p}<0.001$; year: $\left.\chi^{2}=5.31, \mathrm{p}=0.021\right)$, but no significant interaction between year and latitude $\left(\chi^{2}=0.24, \mathrm{df}=1\right.$, $\mathrm{p}=0.62)$. Parameter estimates for these relationships indicated that (1) breeding became $1.98 \pm 0.30 \mathrm{~d}(\mathrm{SE})$ later for every $1^{\circ}$ latitude shift northwards, and thus on average, gannets bred 26 d later in the Faeroe Islands than in northern France; and (2) breeding had become $0.21 \pm 0.09 \mathrm{~d}$ later each year such that on average, birds bred 6 d later in 2007 than in 1980 (Fig. 2). Mean SST was negatively related to timing of breeding (i.e. earlier breeding where mean SST was higher; $\chi^{2}=$ 10.62, $\mathrm{p}=0.0056)$, but this effect disappeared once the latitudinal effect was included in the model $\left(\chi^{2}=2.06\right.$, $\mathrm{p}=0.15)$. Neither NAO nor SST anomalies were statistically related to timing of breeding, regardless of whether the linear temporal trend was included (all $\chi^{2}<1.25$, all $\mathrm{p}>0.25$ ).

\section{DISCUSSION}

\section{Methodology}

Many data used here were by-products of surveys where the primary aim was to estimate gannet population size or breeding success, or to ring or harvest chicks. The conspicuousness of gannets and the long nestling period when chicks are comparatively easy to age (Nelson 1978) allow retrospective estimates of hatch dates to be obtained from brief, single visits to colonies. We calculated median rather than mean annual hatch dates to allow the inclusion of birds still on eggs or brooding chicks too small to be seen clearly and so aged. Our method made 2 key assumptions: (1) losses occurring before the sample of chicks was aged did not distort the primary distribution of laying dates; and (2) feeding conditions were good enough for chicks to develop normally, such that estimated ages were reliable. Data to validate these assumptions directly are lacking. Although feeding conditions for UK seabirds are thought to have deteriorated in recent years (Furness \& Tasker 2000, Mitchell et al. 2004), gannets are considered to be relatively insensitive to changes in prey availability, being buffered against food shortages by their large body size, generalist diet and flexible time budgets (Furness \& Tasker 2000, Lewis et al. 2003, Hamer et al. 2007). Thus, to date, the species has not been involved in any of the catastrophic, food-related breeding failures that have periodically been recorded around the UK (Furness \& Tasker 2000, Mavor et al. 2005, 2006, Wanless et al. 2005a), and breeding success has remained consistently high (e.g. mean productivity at 6 UK colonies between 1986 and 2007, $0.70 \pm 0.01 \mathrm{SE}, \mathrm{n}=94$ colonyyears; JNCC UK Seabird Monitoring Programme unpubl. data).Therefore, it seems unlikely that any major changes in productivity (e.g. increased loss of early hatched chicks or an increased probability of relaying) occurred over the study period, which in turn could have resulted in a systematic bias in the ages of chicks available for sampling. During development, young birds preferentially put resources into body parts that are essential for post-fledging survival (O'Connor 1977); for example, in seabirds, feather growth is prioritised ahead of body mass (Harris 1966, Øyan \& Anker-Nilssen 1996). Given the consistently high breeding success noted above, it seems unlikely that plumage development was disrupted to any great extent, and chick plumage should therefore have been a reliable ageing criterion across the study period.

Clearly the limitations associated with such phenology estimates need to be kept in mind, but the method is probably as robust as many others used to track phenology, such as first egg dates. Thus, we believe that this method has considerable potential, particularly for species such as the gannet where many breeding colonies are in remote locations, and visits are typically infrequent and often of short duration. Future priorities for gannets could include (1) tracking any further changes in timing of breeding in the centre and south of the breeding range as shown here, and (2) providing baseline data for the northernmost colonies in Norway and Iceland for which information is currently lacking (R. T. Barrett pers. comm., A. Petersen pers. comm.). 


\section{Spatial and temporal changes in phenology}

Many reproductive characteristics of birds are related to latitude, with breeding tending to start later at higher latitudes (Baker 1938, Hopkins 1938, Olsen \& Marples 1993). Over a latitudinal range of $14^{\circ}$ $(1540 \mathrm{~km})$ we found evidence of a highly significant latitudinal effect on the timing of gannet breeding, with the median hatch date becoming $1.98 \mathrm{~d}$ later for every $1^{\circ}$ northward shift. Our dataset was restricted to colonies in the middle and southern parts of the gannet's breeding range in the eastern Atlantic. No current information is available on breeding times at northernmost gannetries, but the limited previous data suggest that the latitudinal relationship does not hold; median hatch dates on Hellisey, Iceland, and Hovsflesa, Norway, were 1 and 22 June 1985, respectively (M. L. Tasker pers. comm., R. T. Barrett pers. comm.), much earlier than expected from their latitudes $\left(63^{\circ} 22^{\prime} \mathrm{N}\right.$ and $68^{\circ} 22^{\prime} \mathrm{N}$, respectively). The reason for this discontinuity in the latitudinal trend is unclear, but may be related to the different oceanographic regions in which the colonies are situated (Beaugrand et al. 2002b).

Among terrestrial birds, timing of breeding has typically been advancing in recent decades; in many cases apparently in response to rising air temperatures (see Crick 2004). Equivalent data for marine birds are fewer and, in contrast, indicate that at some colonies breeding is becoming later (Aebischer et al. 1990, Barbraud \& Weimerskirch 2006). Barbraud \& Weimerskirch (2006) speculated that these contrasting phenological responses between terrestrial and marine birds might reflect geographic differences, with evidence for most of the former coming from temperate species while their results were for Antarctic seabirds. However, our findings for northern gannets add to an increasing number of studies of north temperate seabirds that also show breeding getting later (Aebischer et al. 1990, Frederiksen et al. 2004), and thus that the terrestrial/ marine difference is unlikely to simply be a geographic effect.

Both intrinsic (e.g. colony size and/or age) and extrinsic factors (e.g. hydrobiological conditions) could potentially affect breeding time in gannets. The colonies included in our dataset covered a wide range of sizes and ages; for example, St. Kilda, Bass Rock, Ailsa Craig and Grassholm are large, long-established gannetries, while Fair Isle and Troup Head are small and newly colonised. Nevertheless, increased intraspecific interference as the total gannet population has grown (Lewis et al. 2001) may have caused birds to take longer to achieve breeding condition in spring. However, environmental conditions may also have been important. The eastern Atlantic is a highly sea- sonal environment characterised by a pronounced spring plankton bloom primarily controlled by day length and hydrobiological conditions (Pingree et al. 1977). Sea surface temperatures in the region have been increasing, particularly since the late 1980s (Edwards et al. 2007), and the spring bloom has also occurred earlier over this period (Edwards \& Richardson 2004, Sharples et al. 2006). Being homoeothermic, seabirds are unlikely to be physiologically affected by temperature changes of the magnitude so far recorded in the area. However, they feed almost exclusively on invertebrate and/or fish prey that are sensitive to temperature and may have relatively narrow thermal tolerances. Later breeding of seabirds could therefore reflect temperature-induced reductions in prey availability, for example through changes in abundance, distribution or phenology, and many such changes are occurring in the eastern Atlantic (Beaugrand et al. 2002b, Edwards \& Richardson 2004, Richardson \& Schoeman 2004, Perry et al. 2005). Nevertheless, we found no indication that the trend towards later breeding was related to either local or large-scale ocean climate. This emphasizes that understanding the implications of climatic changes for predator-prey interactions is not straightforward, and is particularly challenging in generalist species such as the northern gannet where detailed data on diet and distribution in the pre-breeding period are lacking. It is interesting that latitude explained much more of the betweencolony variation in phenology than mean SST. This indicates that the strong north-south cline in timing of breeding is not directly related to temperature, and suggests that intrinsic responses to photoperiod may be more important.

Our uncertainty of the mechanisms affecting gannet phenology is further increased because detailed time series of annual hatch dates are lacking for most colonies. Thus, while we are confident that breeding has become later over the last $30 \mathrm{yr}$, the lack of runs in annual hatch dates means that we cannot formally test when the change occurred. Qualitative observations from some of the Scottish colonies, e.g. Bass Rock, Ailsa Craig, Hermaness and Sula Sgeir, suggest that most of the change occurred in the early 2000s (Zonfrillo 2005, Nelson 2006, 2007, Okill 2007, D. Macfarlane pers. comm.), but data from Rouzic suggest that the change started earlier and was perhaps more gradual (F. Siorat pers. comm.). Thus, although we found no significant interaction between latitude and year in our analysis, it is possible that some more subtle colony or regional differences are present, and other studies have typically found non-uniform responses to climate change across the full extent of a species' range (Visser et al. 1998, Dunn \& Winkler 1999, Both et al. 2004). 
Alternatively, the consistency of the temporal response across colonies may indicate a common factor operating outside the breeding season and possibly not directly linked to climate change. Evidence for such an effect comes from changes in the over-wintering distribution of adult-plumaged gannets. Thus, observations of birds at sea (S. Garthe pers. comm.), ringing recoveries (R. W. Furness pers. comm.) and locations of birds fitted with geolocators (S. Garthe pers. comm., R. W. Furness pers. comm.) all indicate that gannets now winter further south than previously. A southward extension of the wintering range, and hence increased return distance to the breeding colonies, might result in delayed breeding schedules. Further work on the over-wintering period may clarify the situation.

To the best of our knowledge, our findings provide the first evidence of a trend towards later breeding in a marine predator across a major part of its breeding range. Whether changes in the timing of breeding should be regarded as negative (i.e. environmental change impacting natural populations) or positive (i.e. adaptation to changing conditions) remains unclear (Visser \& Both 2005). However, in many bird species, laying later is associated with fewer young being fledged (Lack 1968), and such an effect has previously been found in gannets (Nelson 1978). A widespread shift towards later breeding could, therefore, potentially lead to lower production of young and might also have adverse consequences for adult and juvenile survival.

Acknowledgements. We are very grateful to the many people listed in the methods for ageing and photographing gannet chicks, allowing us to use their data and answering our queries. Special thanks to D. Thompson and A. Hall (Sea Mammal Research Unit, University of St. Andrews) for photographs of 4 of the most isolated colonies in 2007, to F. Siorat (Ligue pour la Protection des Oiseaux, Station Ornithologique de l'Ile Grande, Réserve Naturelle des Sept-Iles, France) for long-term data from Rouzic, and to D. Shaw (Fair Isle Bird Observatory Trust), J. Swales and S. Smith (Scottish Natural Heritage), and I. Kendall (Royal Society for the Protection of Birds) for access to many unpublished reports and databases. Gannet breeding data were collected as part of the Seabird Monitoring Programme which is coordinated by the Joint Nature Conservation Committee in partnership with the statutory country conservation agencies and other conservation agencies in the UK and the Republic of Ireland. Finally, we are very grateful to D. Grémillet, S. Garthe and R. Furness for comments and suggestions on an earlier version of this manuscript, and to F. Daunt for help with Fig. 1.

\section{LITERATURE CITED}

Aebischer NJ, Coulson JC, Colebrook JM (1990) Parallel long-term trends across four marine trophic levels and weather. Nature 347:753-755

Ash A, Dodd C (2007) Noss NNR 2007 Annual Report. Scottish Natural Heritage, Lerwick
Baker JR (1938) The relation between latitude and breeding season in birds. Proc Zool Soc Lond A 108:557-582

Barbraud C, Weimerskirch H (2006) Antarctic birds breed later in response to climate change. Proc Natl Acad Sci USA 103: 6248-6251

Beaugrand G, Ibanez F, Lindley JA, Reid PC (2002a) Diversity of calanoid copepods in the North Atlantic and adjacent seas: species associations and biogeography. Mar Ecol Prog Ser 232:179-195

Beaugrand G, Reid PC, Ibanez F, Lindley JA, Edwards M (2002b) Reorganization of North Atlantic marine copepod biodiversity and climate. Science 296:1692-1694

Both C, Artemyev AV, Blaauw B, Cowie RJ and others (2004) Large-scale geographical variation confirms that climate change causes birds to lay earlier. Proc R Soc Lond B 271: 1657-1662

Crick HQP (2004) The impact of climate change on birds. Ibis 146(Suppl):48-56

Crick HQP, Sparks TH (1999) Climate change related to egglaying trends. Nature 399:423-424

Crick HQP, Dudley C, Glue DE, Thomson DL (1997) UK birds are laying eggs earlier. Nature 388:526

$>$ Dunn PO, Winkler DW (1999) Climate change has affected the breeding date of tree swallows throughout North America. Proc R Soc Lond B 266:2487-2490

Durant JM, Stenseth NC, Anker-Nilssen T, Harris MP, Thompson PM, Wanless S (2004) Marine birds and climate fluctuation in the North Atlantic. In: Stenseth NC, Ottersen G, Hurrell JW, Belgrano A (eds) Marine ecosystems and climate variation. Oxford University Press, Oxford, p 95-105

Edwards M, Richardson AJ (2004) Impact of climate change on marine pelagic phenology and trophic mismatch. Nature 430:881-884

Edwards M, Johns DG, Licandro P, John AWG, Stevens DP (2007) Ecological status report: results from the CPR survey 2005/2006. SAHFOS Technical Report 4:1-8, Plymouth

- Frederiksen M, Harris MP, Daunt F, Wanless S (2004) Scaledependent climate signals drive breeding phenology of three seabird species. Glob Change Biol 10:1214-1221

Furness RW, Tasker ML (2000) Seabird-fishery interactions: quantifying the sensitivity of seabirds to reductions in sandeel abundance, and identification of key areas for sensitive seabirds in the North Sea. Mar Ecol Prog Ser 202: $253-264$

> Hamer KC, Humphreys EM, Garthe S, Hennicke J and others (2007) Annual variation in diets, feeding locations and foraging behaviour of gannets in the North Sea: flexibility, consistency and constraint. Mar Ecol Prog Ser 338: 295-305

> Harris MP (1966) Breeding biology of the Manx shearwater Puffinus puffinus. Ibis 108:17-33

Hopkins AD (1938) Bioclimates: a science of life and climate relations. US Department of Agriculture, Misc Publ No. 280

Hunt JF, Nelson JB (2008) Breeding dates and success of Bass Rock gannets in 2007. Scott Birds 28:47-49

Lack D (1968) Ecological adaptations for breeding in birds. Methuen, London

Levitus S, Antonov JI, Boyer TP, Stephens C (2000) Warming of the world ocean. Science 287:2225-2229

- Lewis S, Sherratt TN, Hamer KC, Wanless S (2001) Evidence of intra-specific competition for food in a pelagic seabird. Nature 412:816-819

Lewis S, Sherratt TN, Hamer KC, Harris MP, Wanless S (2003) Contrasting diet quality of northern gannets Morus bassanus at two colonies. Ardea 91:167-176

Mavor RA, Parsons M, Heubeck M, Schmitt S (2005) Seabird numbers and breeding success in Britain and Ireland, 
2004. UK Nature Conservation No. 28, Joint Nature Conservation Committee, Peterborough

Mavor RA, Parsons M, Heubeck M, Schmitt S (2006) Seabird numbers and breeding success in Britain and Ireland, 2005. UK Nature Conservation No. 30, Joint Nature Conservation Committee, Peterborough

Mitchell PI, Newton SF, Ratcliffe N, Dunn TE (2004) Seabird populations of Britain and Ireland. T. and A. D. Poyser, London

Møller AP, Flensted-Jensen E, Mardal W (2006) Rapidly advancing laying date in a seabird and the changing advantage of early reproduction. J Anim Ecol 75:657-665

Murray S, Wanless S (1986) The status of the gannet in Scotland 1984-1985. Scott Birds 14:74-85

Nelson JB (1978) The gannet. T. and A. D. Poyser, Berkhamsted

Nelson JB (2002) The Atlantic gannet, 2nd edn. Fenix Books, Norfolk

Nelson JB (2006) Mean laying dates in the northern gannet. Scott Birds 26:50

Nelson JB (2007) Gannet laying dates. Scott Birds 27:69

O'Connor RJ (1977) Differential growth and body composition in altricial passerines. Ibis 119:147-166

Okill D (2007) Late breeding season in northern gannets at Hermaness, Shetland in 2006. Scott Birds 27:76-77

Olsen P, Marples TG (1993) Geographic variation in egg size, clutch size and date of laying of Australian raptors (Falconiformes and Strigiformes). Emu 93:167-179

Øyan HS, Anker-Nilssen T (1996) Allocation of growth in food-stressed Atlantic puffin chicks. Auk 113:830-841

Parmesan C, Yohe G (2003) A globally coherent fingerprint of climate change impacts across natural systems. Nature 421:37-42

Patterson HD, Thompson R (1971) Recovery of inter-block information when block sizes are unequal. Biometrika 58: 545-554

Perry AL, Low PJ, Ellis JR, Reynolds JD (2005) Climate change and distribution shifts in marine fishes. Science 308:1912-1915

Pingree RD, Maddock L, Butler EI (1977) The influence of bio-

Editorial responsibility: Matthias Seaman,

Oldendorf/Luhe, Germany logical activity and physical stability in determining the chemical distributions of inorganic phosphate, silicate and nitrate. J Mar Biol Assoc UK 57:1065-1073

> Reed TE, Wanless S, Harris MP, Frederiksen M, Kruuk LEB, Cunningham EJA (2006) Responding to environmental change: plastic responses vary little in a synchronous breeder. Proc R Soc Lond B 273:2713-2719

Richardson AJ, Schoeman DS (2004) Climate impact on plankton ecosystems in the Northeast Atlantic. Science 305:1609-1612

Sharples J, Ross ON, Scott BE, Greenstreet SPR, Fraser H (2006) Inter-annual variability in the timing of stratification and the spring bloom in the North-western North Sea. Cont Shelf Res 26:733-751

Sykes T, Bliss K (2005) Noss NNR annual report 2005. Scottish Natural Heritage, Lerwick

Sykes T, Bliss K (2006) Noss NNR annual report 2006. Scottish Natural Heritage, Lerwick

Thomas G (2005) Hermaness and Keen of Hamar NNR annual report 2005. Scottish Natural Heritage, Lerwick

- Visser ME, Both C (2005) Shifts in phenology due to climate change: the need for a yardstick. Proc R Soc Lond B 272: 2561-2569

Visser ME, van Noodwijk AJ, Tinbergen JM, Lessells CM (1998) Warmer springs lead to mistimed reproduction in great tits (Parus major). Proc R Soc Lond B 265: $1867-1870$

Walther GR, Post E, Convey P, Menzel A and others (2002) Ecological responses to recent climate change. Nature 416:389-395

Wanless S, Matthews J, Bourne WRP (1996) The Troup Head gannetry. Scott Birds 18:214-221

Wanless S, Harris MP, Redman P, Speakman J (2005a) Low fish quality as a probable cause of a major seabird breeding failure in the North Sea. Mar Ecol Prog Ser 294:1-8

Wanless S, Murray S, Harris MP (2005b) The status of northern gannet in Britain \& Ireland in 2003/04. Br Birds 98: 280-294

Zonfrillo B (2005) The Ailsa Craig gannetry in 2004. Br Birds 98:551-555

Submitted: April 23, 2008; Accepted: August 28, 2008

Proofs received from author(s): October 20, 2008 